\title{
Nucleation and Crystal Growth in Laser-Patterned Lines in Glasses
}

\author{
Takayuki Komatsu* and Tsuyoshi Honma \\ Department of Materials Science and Technology, Nagaoka University of Technology, Nagaoka, Japan
}

Laser-induced crystallization is a new method for the design and control of the crystallization of glasses and opens a new door in the study of nucleation and crystal growth in glasses. Nonlinear optical $\mathrm{Sm}$-doped $\beta-\mathrm{BaB}_{2} \mathrm{O}_{4}(\beta-\mathrm{BBO})$ crystal lines were patterned by continuous-wave $\mathrm{Yb}: \mathrm{YVO}_{4}$ fiber laser (wavelength $1080 \mathrm{~nm}$ ) in $8 \mathrm{Sm}_{2} \mathrm{O}_{3}-42 \mathrm{BaO}-50 \mathrm{~B}_{2} \mathrm{O}_{3}$ glass as an example, and nucleation and crystal growth behaviors in the laser-patterned bending and crossing lines were examined. It was confirmed that the growth of $c$-axis oriented $\beta$-BBO crystals follows along the laser scanning direction even if laser scanning direction changes. The model of self-organized homo-epitaxial crystal growth was demonstrated for the orientation of $\beta$-BBO crystals at the crossing point of two lines, in which the first crystal line at the crossing point acts as nucleation site for the second crystal line. This study proposes a new crystal growth technology.

Keywords: laser patterning, nucleation, crystal growth, homo-epitaxial, nonlinear optical crystal

\section{OPEN ACCESS}

Edited by:

Wolfram Höland,

Ivoclar Vivadent AG, Liechtenstein

Reviewed by: Ana Candida Martins Rodrigues, Universidade Federal de São Carlos,

Brazil

Akihiko Sakamoto,

OLED Material Solutions, Japan

*Correspondence:

Takayuki Komatsu

komatsu@mst.nagaokaut.ac.jp

Specialty section:

This article was submitted

to Glass Science,

a section of the journal

Frontiers in Materials

Received: 15 May 2016 Accepted: 01 July 2016

Published: 14 July 2016

Citation:

Komatsu T and Honma T (2016) Nucleation and Crystal Growth in Laser-Patterned Lines in Glasses.

Front. Mater. 3:32.

doi: 10.3389/fmats.2016.00032

\section{INTRODUCTION}

For a deep understanding of the crystallization of glasses and for development of new functional glass-ceramics, the design and control of nucleation and crystal growth are extremely important. One of the most affecting points to this issue is glass composition, because the nucleation behavior and the kind of crystals formed in a given glass depend largely on the chemical composition of the glass. Heat treatment condition such as temperature, time, and atmosphere is also important for the control of nucleation and crystal growth rates in glasses. Usually, glass-ceramics are synthesized through heat treatment of glasses in an electric furnace, and various functional glass-ceramics being available for practical applications have been developed (Beall and Pinckney, 1999; Sakamoto and Yamamoto, 2010; Höland and Beall, 2012).

Spatially selected patterning of crystals in glasses by laser irradiation, i.e., laser-induced crystallization, is also extremely attractive, which is a new method for the design and control of the crystallization of glasses and also opens a new door in the study of nucleation and crystal growth in glasses (Komatsu et al., 2007; Komatsu and Honma, 2013; Inoue et al., 2015; Komatsu, 2015). In the laser-induced crystallization, a steep temperature gradient is created in the laser-irradiated local region, and such a steep temperature gradient is moved along laser scanning direction, consequently providing the patterning of crystals with high orientation. In the laser-induced crystallization, therefore, it is possible to design spatially nucleation site and control crystal growth direction. So far, various crystals with high orientation such as ferroelectric $\mathrm{LiNbO}_{3}$ (Honma and Komatsu, 2010; Komatsu et al., 2011), multi-ferroic $\beta$ ' $-\mathrm{RE}_{2}\left(\mathrm{MoO}_{4}\right)_{3}$ (RE, rare earth) (Tsukada et al., 2009; Suzuki et al., 2014), nonlinear optical $\mathrm{Li}_{2} \mathrm{Si}_{2} \mathrm{O}_{5}$ (Honma et al., 2008a,b), $\mathrm{LaBGeO}_{5}$ (Stone et al., 2010), SbSI (Gupta et al., 2011), and oxyfluoride $\mathrm{BaAlBO}_{3} \mathrm{~F}_{2}$ (Shinozaki et al., 2012) have been patterned in glasses.

Recently, nonlinear optical oxyfluoride $\mathrm{BaAlBO}_{3} \mathrm{~F}_{2}$ crystal lines were patterned in $\mathrm{BaF}_{2}-\mathrm{Al}_{2} \mathrm{O}_{3^{-}}$ $\mathrm{B}_{2} \mathrm{O}_{3}$ glasses, and the model of "self-organized homo-epitaxial crystal growth" has been proposed for the crystal orientation at the crossing point of two laser-patterned lines (Shinozaki et al., 2015). 
This finding gives new potential for future application in the crystallization of glasses. It is of importance to confirm the self-organized homo-epitaxial crystal growth in other glasses, and to demonstrate this growth as a common phenomenon in the laser-induced crystallization. In this work, crossing lines of nonlinear optical $\beta-\mathrm{BaB}_{2} \mathrm{O}_{4}(\beta-\mathrm{BBO})$ crystal were patterned by laser irradiation in $\mathrm{Sm}_{2} \mathrm{O}_{3}-\mathrm{BaO}-\mathrm{B}_{2} \mathrm{O}_{3}$ glasses, and nucleation and crystal growth behaviors at the crossing point were examined from polarized optical microscope (POM) observations. So far, the patterning of highly oriented crystal lines (not crossing lines) of $\beta$-BBO in some glasses has been realized (Honma et al., 2003; Suzuki et al., 2012, 2013; Ogawa et al., 2013; Nishii et al., 2015), and thus, $\beta$-BBO crystal would be a good example for the study of nucleation and crystal growth in the laser-induced crystallization in glasses.

\section{EXPERIMENTAL SECTION}

A glass with the composition of $8 \mathrm{Sm}_{2} \mathrm{O}_{3}-42 \mathrm{BaO}-50 \mathrm{~B}_{2} \mathrm{O}_{3}$ (mol\%) was prepared by melt quenching. Commercial powders of reagent grade $\mathrm{Sm}_{2} \mathrm{O}_{3}, \mathrm{BaCO}_{3}$, and $\mathrm{H}_{3} \mathrm{BO}_{3}$ were melted in a platinum crucible at $1200^{\circ} \mathrm{C}$ for $40 \mathrm{~min}$ in an electric furnace. The melts were poured onto an iron plate and pressed to a thickness of $\sim 1.5 \mathrm{~mm}$ by another iron plate. Glass transition $\left(T_{\mathrm{g}}\right)$ and crystallization peak temperatures $\left(T_{\mathrm{p}}\right)$ were determined by using differential thermal analysis (DTA) at a heating rate of $10 \mathrm{~K} / \mathrm{min}$. The quenched glasses were annealed at $T_{\mathrm{g}}$ for $30 \mathrm{~min}$ to release internal stresses (e.g., Ogawa et al., 2013).

Glasses were mechanically polished to a mirror finish with $\mathrm{CeO}_{2}$ powders. Glasses were irradiated by continuous-wave $\mathrm{Yb}: \mathrm{YVO}_{4}$ fiber laser (beam shape: single mode and $\pm 1 \mathrm{~nm}$ bandwidth) with a wavelength of $\lambda=1080 \mathrm{~nm}$ using objective lens (magnification: 50 times, numerical aperture: $\mathrm{NA}=0.8$ ). The laser beam was unpolarized, and the diameter of laser spot was $2-3 \mu \mathrm{m}$. Plate-shaped glasses with a thickness of $\sim 1 \mathrm{~mm}$ were put on the stage and mechanically moved during laser irradiation to pattern crossing crystal lines.

Raman scattering and micro-photoluminescence (PL) spectra at room temperature for laser-patterned lines were measured with a laser microscope (Tokyo Instruments Co., Nanofinder) operated at $\mathrm{Ar}^{+}$laser $(\lambda=488 \mathrm{~nm})$. Second harmonic generations (SHGs) were measured using a Q-switched Nd: yttrium aluminum garnet (YAG) laser with $\lambda=1064 \mathrm{~nm}$, in which linearly polarized incident light was used and second harmonic (SH) light $(\lambda=532 \mathrm{~nm})$ was detected. Conventional POM observations for laser-irradiated parts were carried out using an apparatus of Olympus-BX51, in which the crossed polarizer and analyzer were used together with a sensitive color plate. Light being used is white light. Furthermore, samples placed at the stage were rotated, and the change in interference color was observed.

\section{RESULTS AND DISCUSSION}

The glass of $8 \mathrm{Sm}_{2} \mathrm{O}_{3}-42 \mathrm{BaO}-50 \mathrm{~B}_{2} \mathrm{O}_{3}$ has the values of $T_{\mathrm{g}}=566^{\circ} \mathrm{C}$ and $T_{\mathrm{p}}=681^{\circ} \mathrm{C}$. Sm ${ }^{3+}$ ions in the glass have the optical absorption coefficient ( $\alpha$ : at room temperature) of $\alpha=10.1 \mathrm{~cm}^{-1}$ at $\lambda=1080 \mathrm{~nm}$ (Yb: $\mathrm{YVO}_{4}$ fiber laser) (Ogawa et al., 2013).
Considering the data on the quality of $\beta$-BBO crystals patterned by laser irradiation in our research group (e.g., Ogawa et al., 2013), the condition of laser power $P=0.8 \mathrm{~W}$ and laser scanning speed of $S=4 \mu \mathrm{m} / \mathrm{s}$ was used for the patterning of $\beta$-BBO crystals in the glass. In this study, first the crystal growth behavior of $\beta$-BBO crystals in straight, bending, and spiral lines is discussed briefly, and then, the nucleation and crystal growth behaviors of $\beta-\mathrm{BBO}$ crystals at the crossing point of two lines are described. This step would be valuable for the discussion on the self-organized homoepitaxial crystal growth in the crossing lines of the glass. The data on POM observations on straight, bending, and spiral lines have been already reported in the previous paper (Ogawa et al., 2013), but the quantitative data on the azimuthal dependence of SHG signals for these lines was measured in this study.

\section{Crystal Growth and Orientation in Straight, Bending, and Spiral lines}

The discrete straight and bending (bending angle: $45^{\circ}$ ) lines with $\beta$-BBO crystals (the width of lines: $5 \mu \mathrm{m}$ ) were patterned by laser irradiation with $P=0.8 \mathrm{~W}$ and $S=4 \mu \mathrm{m} / \mathrm{s}$ at the surface of $8 \mathrm{Sm}_{2} \mathrm{O}_{3}-42 \mathrm{BaO}-50 \mathrm{~B}_{2} \mathrm{O}_{3}$ glass. It is possible to form $\beta$ - $\mathrm{BBO}$ crystalline dots initially at a given place by laser irradiation without moving but cracks are frequently induced around crystalline dots after stopping or moving of laser irradiation. Therefore, in this study, $\beta$-BBO crystal particles synthesized by the crystallization of the glass in an electric furnace were used as the initial nucleation site. That is, laser was first irradiated (focused) onto a $\beta-\mathrm{BBO}$ crystal particle placed at the glass surface and then scanned with the scanning speed of $S=4 \mu \mathrm{m} / \mathrm{s}$.

The azimuthal dependence of SHG signals for the straight and bending lines consisting of $\beta-\mathrm{BBO}$ crystals is shown in Figure 1. The formation of $\beta$-BBO crystals in these lines has been confirmed in the previous paper (e.g., Ogawa et al., 2013). The POM photographs for these lines are included in Figure 1. The

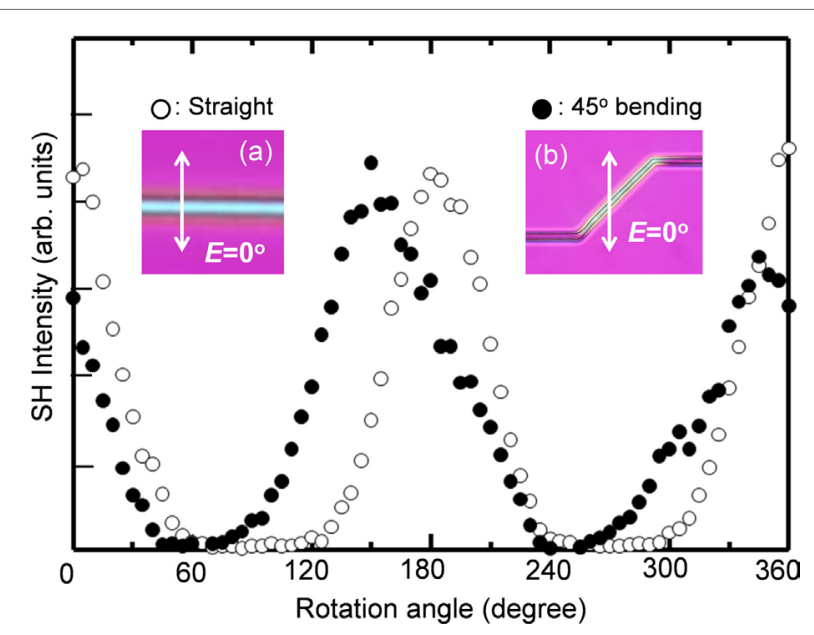

FIGURE 1 | Azimuthal dependence of SHG signals for the straight and bending (bending angle: $45^{\circ}$ ) lines consisting of $\beta$-BBO crystals in the glass. (A,B) are conventional POM photographs for these lines. 
maximum $\mathrm{SH}$ intensities for the straight line are observed at the rotation angles of $\sim 0^{\circ}$ and $\sim 180^{\circ}$, and the minimum $\mathrm{SH}$ intensities are located at $90^{\circ}$ and $270^{\circ}$. In $\beta-\mathrm{BBO}$, the presence of $\left[\mathrm{B}_{3} \mathrm{O}_{6}\right]^{3-}$ anionic hexagonal groupings slightly distorted with a threefold axis is the origin of the large second-order nonlinear optical coefficient $\left(d_{22} \sim 2 \mathrm{pm} / \mathrm{V}\right)$. The effective second-order nonlinear optical coefficient, $d_{\mathrm{eff}}$, is given by the equation of $d_{\mathrm{eff}}=d_{22} \cos ^{2} \theta$. It was confirmed that the $\mathrm{SH}$ intensity for the straight line shown in Figure 1 changes as a function of $\cos ^{2} \theta$, indicating that $\beta$-BBO crystals in the straight line are highly oriented and grow with the $c$-axis orientation along the laser scanning direction (e.g., Honma et al., 2003; Ogawa et al., 2013). The $c$-axis orientation of $\beta$-BBO crystals has been already proposed in the previous papers (e.g., Honma et al., 2003; Ogawa et al., 2013).

On the other hand, as can be seen in Figure 1, the maximum $\mathrm{SH}$ intensities for the bending line are observed at the rotation angles of $\sim 150^{\circ}$ and $\sim 345^{\circ}$, and the minimum $\mathrm{SH}$ intensities are located at $\sim 50^{\circ}$ and $255^{\circ}$. In particular, when compared with the straight line, it is found that the rotation angle providing the maximum $\mathrm{SH}$ intensity in the bending line shifts toward the lower angle with the magnitude of $\sim 30^{\circ}$. Furthermore, it should be pointed out that the profile of $\mathrm{SH}$ intensities against the rotation angle in the bending line is broad when compared with the straight line. It is regarded that the bending line with the bending angle of $45^{\circ}$ consists of two components of straight line part and bending line part against the linearly polarized incident laser for SHG measurements, i.e., the components of two rotation angles of $\theta$ and $\theta+45^{\circ}$. In other words, the $\mathrm{SH}$ intensity for the bending line would be expressed as a sum of two contributions (functions) of $\cos ^{2} \theta$ and $\cos ^{2}(\theta+45)$. This would be the reason for the shift of the peak position of the maximum $\mathrm{SH}$ intensity and the broadness of the profile of $\mathrm{SH}$ intensity in the bending line compared with the straight line. Indeed, the profile of $\mathrm{SH}$ intensity for the bending line was well fitted with a function of $f(\theta)=\cos ^{2} \theta+\cos ^{2}(\theta+45)$. The results shown in Figure 1 also indicate that the $c$-axis orientation of $\beta$-BBO crystals is kept even in the bending line.

The azimuthal dependence of SHG signals for the spiral line consisting of $\beta$-BBO crystals is shown in Figure 2. The POM photographs for this lines and the $\mathrm{SH}$ wave images (the intensities of green light with $\lambda=532 \mathrm{~nm}$ ) observed are included in Figure 2. SHGs are detected at all rotation angles, and any specific (critical) angles providing maximum or minimum $\mathrm{SH}$ intensities are not observed. In $\beta$-BBO crystals, strong SHGs are observed when the direction of the electric field in the linearly polarized incident lasers $(E)$ is parallel to the direction of the polarization in $\left[\mathrm{B}_{3} \mathrm{O}_{6}\right]^{3-}$ units $\left(P_{\mathrm{o}}\right)$, i.e., $E / / P_{\mathrm{o}}$. In the spiral line with the $c$-axis orientation of $\beta$ - $\mathrm{BBO}$ crystals, the configuration of $E / / P_{\mathrm{o}}$ is always achieved at any angles, and as a result, it is expected that similar $\mathrm{SH}$ intensities are detected in all rotation angles as shown in Figure 2. The results shown in Figure 2 also demonstrate that the $c$-axis orientation of $\beta$-BBO crystals is kept even in the spiral line.

From the $c$-axis orientation of $\beta$-BBO crystal lines demonstrated in Figures $\mathbf{1}$ and 2, it is considered that the preferential crystal growth direction is the $c$-axis. $\beta$-BBO with a crystal structure of R3c has the lattice parameters of $a=b=1.2547 \mathrm{~nm}$ and $c=1.2736 \mathrm{~nm}$ (Eimerl et al., 1987), indicating that the

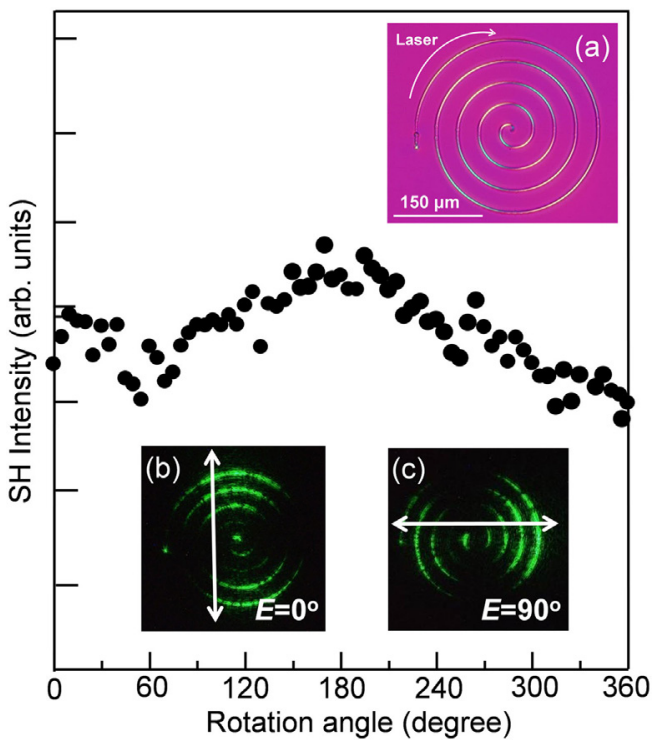

FIGURE 2 | Azimuthal dependence of SHG signals for the spiral line consisting of $\boldsymbol{\beta}$-BBO crystals in the glass. (A) is the conventional POM photograph for the line, and $\mathbf{( B , C )}$ are SHG microscope observations. $E$ is the direction of electric field of the incident laser for SHG measurements.

difference in the lattice parameters is very small. As well known, however, $\beta$-BBO has a large anisotropic structure, in which planar $\left[\mathrm{B}_{3} \mathrm{O}_{6}\right]^{3-}$ units stack along the $c$-axis direction, and $\mathrm{Ba}^{2+}$ ions are located between stacked $\left[\mathrm{B}_{3} \mathrm{O}_{6}\right]^{3-}$ units. The thermal expansion coefficient $(\alpha)$ of $\beta$-BBO is $\alpha=4 \times 10^{-6} / \mathrm{K}$ for the $a$-axis and $\alpha=36 \times 10^{-6} / \mathrm{K}$ for the $c$-axis, indicating that the chemical bond strength between $\mathrm{Ba}^{2+}$ and planar $\left[\mathrm{B}_{3} \mathrm{O}_{6}\right]^{3-}$ units is weaker than that between $\left[\mathrm{B}_{3} \mathrm{O}_{6}\right]^{3-}$ units. In other words, it is expected that the modification in the bonding distance between $\mathrm{Ba}^{2+}$ and planar $\left[\mathrm{B}_{3} \mathrm{O}_{6}\right]^{3-}$ units is more flexible. These structural features of $\beta$-BBO would induce the $c$-axis orientation even for the bending and spiral lines as shown in Figures 1 and 2 . That is, it would be possible to change or rotate gradually the $c$-axis direction at the bending or curved points.

The nucleation and crystal growth rates of $\beta$-BBO crystals in $8 \mathrm{Sm}_{2} \mathrm{O}_{3}-42 \mathrm{BaO}-50 \mathrm{~B}_{2} \mathrm{O}_{3}$ glass have not been reported so far. It is well known that a glass with the composition of $40 \mathrm{BaO}$ $20 \mathrm{TiO}_{2}-40 \mathrm{SiO}_{2}$ displays the highest internal nucleation $(I)$ rare for fresnoite $\mathrm{Ba}_{2} \mathrm{TiSi}_{2} \mathrm{O}_{8}$ crystals so far measured in inorganic glasses (Cabral et al., 2003), i.e., $I \sim 10^{17} / \mathrm{m}^{3}$ s. This nucleation rare of $I \sim 10^{17} / \mathrm{m}^{3}$ s equals to $I \sim 0.1 / \mu \mathrm{m}^{3}$ s. The maximum steadystate nucleation rates $\left(I_{\max }\right)$ for 51 silicate glasses with different compositions have been summarized as a function of reduced glass transition temperature $\left(T_{\mathrm{gr}}\right)\left(T_{\mathrm{gr}}=T_{\mathrm{g}} / T_{\mathrm{m}}, T_{\mathrm{m}}\right.$ is the melting temperature) (Fokin et al., 2003). The silicate glasses summarized have mainly the values of $I_{\max }=10^{9}-10^{13} / \mathrm{m}^{3} \mathrm{~s}$, corresponding to the values of $I_{\max }=10^{-9}-10^{-5} / \mu \mathrm{m}^{3} \mathrm{~s}$. The value of $I_{\max } \sim 10 / \mathrm{mm}^{3} \mathrm{~s}$, corresponding to $10^{-8} / \mu \mathrm{m}^{3} \mathrm{~s}$, has been reported for lithium disilicate $\left(\mathrm{Li}_{2} \mathrm{O} \cdot 2 \mathrm{SiO}_{2}\right)$ glass (Deubener, 2000). In the laser-induced crystallization, only spatially limited region, i.e., the region of $10-20 \mu \mathrm{m}$, is heated locally, and furthermore, the keeping period 
for high temperature in a given laser-irradiated position is short due to the laser scanning with speeds of $S=1-10 \mu \mathrm{m} / \mathrm{s}$ and also to the heat dissipation to the surrounding glassy part (not laser-irradiated part). These features of small heating region and short keeping time at a fixed region would result in the small probability of nucleation during laser scanning. Indeed, highly (c-axis) oriented $\mathrm{Li}_{2} \mathrm{Si}_{2} \mathrm{O}_{5}$ crystal lines have been patterned in $\mathrm{Li}_{2} \mathrm{O} \cdot 2 \mathrm{SiO}_{2}$ glass without causing any new nucleation during laser scanning (Honma et al., 2008a,b). The results shown in Figures 1 and 2 propose that at least, at the laser irradiation condition of $P=0.8 \mathrm{~W}$ and $S=4 \mu \mathrm{m} / \mathrm{s}$, only the crystal growth of $\beta$-BBO is taking place during the laser scanning in $8 \mathrm{Sm}_{2} \mathrm{O}_{3}-42 \mathrm{BaO}-50 \mathrm{~B}_{2} \mathrm{O}_{3}$ glass without causing any nucleation, and this would be one of the key points for the laser patterning of $\beta$-BBO crystals with high orientation. It should be pointed out that highly oriented $\mathrm{Ba}_{2} \mathrm{TiSi}_{2} \mathrm{O}_{8}$ crystal lines have been patterned by laser irradiation in $40 \mathrm{BaO}-20 \mathrm{TiO}_{2}-40 \mathrm{SiO}_{2}$ glass, although $\mathrm{Ba}_{2} \mathrm{TiSi}_{2} \mathrm{O}_{8}$ nanocrystals are formed by heat treatment in an electric furnace (Enomoto et al., 2007; Honma et al., 2008a,b; Maruyama et al., 2008). Similar behaviors have been observed in the laser patterning and nano-scaled crystallization of the formation of nonlinear optical $\mathrm{BaAlBO}_{3} \mathrm{~F}_{2}$ crystals in $50 \mathrm{BaF}_{2}-25 \mathrm{Al}_{2} \mathrm{O}_{3}-25 \mathrm{~B}_{2} \mathrm{O}_{3}$ glass (Shinozaki et al., 2012). In the crystallization of $\mathrm{CaF}_{2}$ in $\mathrm{CaF}_{2}-\mathrm{Al}_{2} \mathrm{O}_{3}-\mathrm{SiO}_{2}-$ based oxyfluoride glasses, however, it has been reported that lines consisting of $\mathrm{CaF}_{2}$ nanocrystals have been patterned by laser irradiation as similar to the case in heat treatment in an electric furnace (Kanno et al., 2009; Shinozaki et al., 2013). That is, lines consisting of the assembly of $\mathrm{CaF}_{2}$ nanocrystals have been patterned, but the patterning of highly oriented $\mathrm{CaF}_{2}$ single crystal lines have not been reported so far. The nucleation and crystal growth behaviors in the laser-induced crystallization, therefore, depend not only on laser irradiation condition but also on glass composition.

The laser-induced crystallization technique proposed and applied in our group is based perfectly on the thermal effect (heating) as similar to the crystallization in an electric furnace. Therefore, basically, the crystalline phase formed in the laserinduced crystallization in a given glass is the same as that formed in the crystallization in an electric furnace. In this sense, it should be emphasized that even in the laser-induced crystallization, the design of the system and composition of base glasses is still a key point for the patterning of crystals with high qualities. That is, even in the laser-induced crystallization, the design and control of the morphology of crystals depend largely on the chemical composition of a given glass.

\section{Nucleation and Homo-Epitaxial Crystal Growth in Crossing Lines}

As indicated in the above section, through the use of optimal laser power and scanning speed, it is possible to depress nucleation during laser scanning and to induce homogeneous crystal growth providing the patterning of highly oriented $\beta$-BBO crystal lines in $8 \mathrm{Sm}_{2} \mathrm{O}_{3}-42 \mathrm{BaO}-50 \mathrm{~B}_{2} \mathrm{O}_{3}$ glass. Here, the nucleation and crystal growth behaviors of $\beta$-BBO crystals in the laser-induced crystallization are discussed more in detail by patterning crossing lines. A schematic illustration for crossing line experiments is shown in Figure 3. First, a discrete straight line consisting of highly oriented $\beta$-BBO crystals was patterned by laser irradiation with $P=0.8 \mathrm{~W}$ and $S=4 \mu \mathrm{m} / \mathrm{s}$ in $8 \mathrm{Sm}_{2} \mathrm{O}_{3}-42 \mathrm{BaO}-50 \mathrm{~B}_{2} \mathrm{O}_{3}$ glass, in which a $\beta$-BBO crystal particle synthesized by the crystallization of the glass in an electric furnace was used as an initial nucleation site. Then, the second laser irradiation with $P=0.8 \mathrm{~W}$ and $S=1-4 \mu \mathrm{m} / \mathrm{s}$ was carried out against the first line with the crossing angle of $90^{\circ}$ (perpendicularly). In the second line patterning, any $\beta$ - $\mathrm{BBO}$ crystal particles were not used, and thus, the laser irradiation does not induce any crystallization before crossing against the first line but just only the change in the glass structure (refractive index change).

The POM photograph for the crossing lines is shown in Figure 4. In the POM observations, the crossed polarizer and analyzer were used, and the appearance of bright and homogeneous interference color indicates the formation of nonlinear optical crystals. On the other hand, structurally isotropic glassy materials do not give any interference color. It is, therefore, concluded from the POM photograph in Figure 4 that, in the second lines with

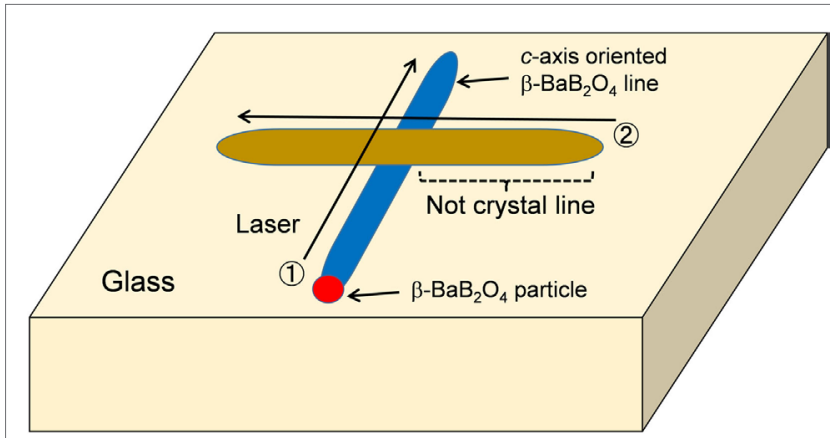

FIGURE 3 | Schematic experimental procedure for the patterning of crossing crystal lines. First, the crystal line (1) was patterned, and then, the second laser irradiations (2) were carried out for the first line with the crossing angle of $90^{\circ}$

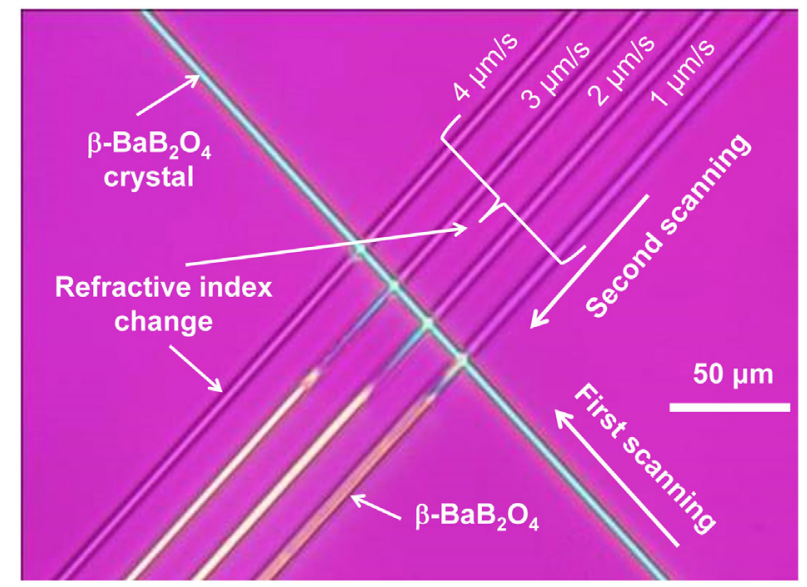

FIGURE 4 | POM photograph for the crossing lines. In the second lines, the laser scanning speeds of $S=1,2,3$, and $4 \mu \mathrm{m} / \mathrm{s}$ were used. 
the laser scanning speeds of $S=1,2$, and $3 \mu \mathrm{m} / \mathrm{s}$, the formation of crystals is induced after crossing against the first crystal line, although any crystals were not formed before crossing. In the second line with $S=4 \mu \mathrm{m} / \mathrm{s}$, any crystallization was not induced even after crossing. These results indicate that nucleation and crystal growth behaviors at the crossing region depend on the scanning speed of the second line patterning. That is, the scanning with low speed is more effective for the nucleation and crystal growth at the crossing region.

The micro-Raman scattering spectrum at room temperature for the crystalline part in the second line $(P=0.8 \mathrm{~W}, S=1 \mu \mathrm{m} / \mathrm{s})$ after crossing is shown in Figure 5. The Raman bands are assigned to $\beta$-BBO crystal (Suzuki et al., 2012), indicating that nonlinear optical crystals (i.e., $\beta$-BBO) formed in the second line after crossing is the same as that in the first line consisting of $\beta$-BBO. As can be seen in Figure 5, the intensities of Raman bands in the second line (b) are much larger than those in the first line (a). The first line consisting of $\beta$-BBO crystals was patterned with the condition of $P=0.8 \mathrm{~W}$ and $S=4 \mu \mathrm{m} / \mathrm{s}$. On the other hand, the second line was patterned with $P=0.8 \mathrm{~W}$ and $S=1 \mu \mathrm{m} / \mathrm{s}$. As shown in Figure 4, the formation behavior of $\beta$-BBO crystals after crossing depends on the laser scanning speed. The Raman scattering spectra shown in Figure 5, i.e., the difference in the Raman band intensity between the first line (a) and the second line (b), therefore, suggest that the amount of $\beta$-BBO crystals increases with the decrease in the laser scanning speed from 4 to $1 \mu \mathrm{m} / \mathrm{s}$, and also, their quality might be improved in the condition of low laser scanning speed. Considering crystal growth kinetics in glass, low laser scanning speed, i.e., keeping high temperature for long period, would be favorable for crystal growth. Of course, however, optimal laser irradiation condition (optimal laser power and scanning speed) is required for the pattering of homogeneous crystal lines (Honma et al., 2005; Inoue et al., 2015).

The micro PL spectrum at room temperature for the second line after crossing is shown in Figure 6. Four luminescence

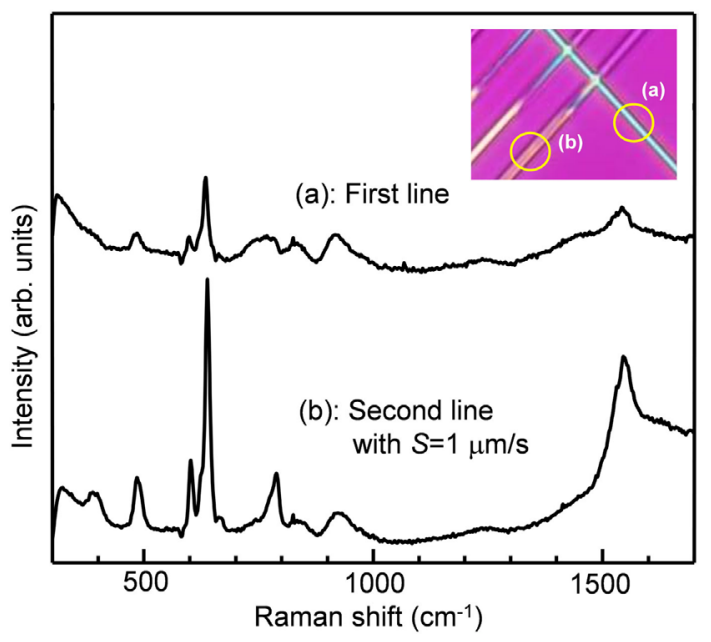

FIGURE 5 | Micro-Raman scattering spectra at room temperature for the first (A) and second (B) lines patterned by laser irradiation. peaks are observed at $\sim 565, \sim 600, \sim 645$, and $\sim 705 \mathrm{~nm}$. These are typical emissions of $\mathrm{Sm}^{3+}$ assigned to ${ }^{4} \mathrm{G}_{5 / 2} \rightarrow{ }^{6} \mathrm{H}_{\mathrm{J}}$, i.e., ${ }^{4} \mathrm{G}_{5 / 2} \rightarrow{ }^{6} \mathrm{H}_{5 / 2}$ at $565 \mathrm{~nm},{ }^{4} \mathrm{G}_{5 / 2} \rightarrow{ }^{6} \mathrm{H}_{7 / 2}$ at $600 \mathrm{~nm},{ }^{4} \mathrm{G}_{5 / 2} \rightarrow{ }^{6} \mathrm{H}_{9 / 2}$ at $645 \mathrm{~nm}$, and ${ }^{4} \mathrm{G}_{5 / 2} \rightarrow{ }^{6} \mathrm{H}_{11 / 2}$ at $705 \mathrm{~nm}$. Since there is no peaks at around $683 \mathrm{~nm}$ $\left({ }^{5} \mathrm{D}_{0} \rightarrow{ }^{7} \mathrm{~F}_{0}\right), 725 \mathrm{~nm}\left({ }^{5} \mathrm{D}_{0} \rightarrow{ }^{7} \mathrm{~F}_{2}\right)$, and $760 \mathrm{~nm}\left({ }^{5} \mathrm{D}_{0} \rightarrow{ }^{7} \mathrm{~F}_{3}\right)$ attributing to $\mathrm{Sm}^{2+}$, samarium ions exist at trivalent $\mathrm{Sm}^{3+}$ in the second line after crossing. That is, there is no change in the valence of Sm ions during laser irradiation. The first and second lines show strong PL intensities compared with the glassy part (not laserirradiated part), suggesting that some $\mathrm{Sm}^{3+}$ ions are incorporated into $\beta$-BBO crystals. It is, therefore, considered that $\mathrm{Sm}^{3+}$-doped $\beta-\mathrm{BaB}_{2} \mathrm{O}_{4}$ crystals are formed in the lines patterned by laser irradiation. It is noted that the intensities of PL spectra in the second line (b) $(S=1 \mu \mathrm{m} / \mathrm{s})$ are much larger than those in the first line (a) $(S=4 \mu \mathrm{m} / \mathrm{s})$, as similar to Raman scattering spectra (Figure 5). The PL spectra shown in Figure 6, therefore, suggest that the amount of $\mathrm{Sm}^{3+}$-doped $\beta$-BBO crystals formed in the second line after crossing is larger than that in the first line. The incorporation of $\mathrm{Sm}^{3+}$ into $\beta-\mathrm{BaB}_{2} \mathrm{O}_{4}$ crystals has been also proposed even in the discrete straight line (Honma et al., 2004).

As indicated in Figures 1 and 4, $\beta$-BBO crystals with the $c$-axis orientation are patterned in the first crystal line. Furthermore, it is found that the nucleation and crystal growth of $\beta$ - $\mathrm{BBO}$ crystals occur effectively at the crossing region of two lines. In order to look at the crystallization behavior at the crossing region more in detail, the POM photograph focusing the crossing region in the second line patterned with $S=2 \mu \mathrm{m} / \mathrm{s}$ is again shown in Figure 7. It is found that the second line just after crossing has a light color, being the same as that in the first line consisting of the $c$-axis oriented $\beta$-BBO crystals. The same color means the same retardation, i.e., the same crystal orientation of nonlinear optical crystals. It is, therefore, considered that the orientation of $\beta$-BBO crystals in the second line after crossing is the same as that in the first line. It is seen that the homogeneous light blue color in the second line changes to other color in the part beyond the

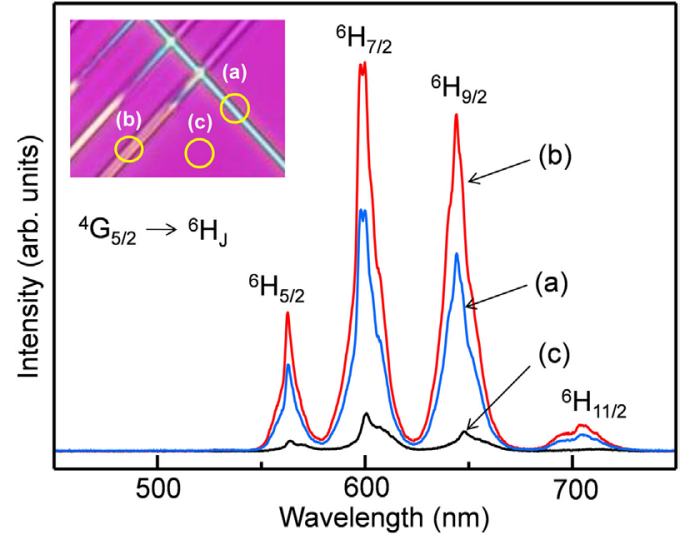

FIGURE 6 | Micro-photoluminescence (PL) spectra at room temperature for the first $(A)$ and second $(B)$ lines patterned by laser irradiation. The PL spectrum for the glassy part (C) (not laser-irradiated part) is also shown. 
distance of about $20 \mu \mathrm{m}$ from the crossing point. This means that the orientation of $\beta$-BBO crystals in this part changes gradually. Considering the crystal growth mechanism in the crossing line experiments, it is suggested that the side plane of the first $\beta$-BBO crystal line acts as the nucleation site for the crystallization in the second line.

The difference in the lattice parameters $(a=b=1.2547 \mathrm{~nm}$ and $c=1.2736 \mathrm{~nm}$ ) in $\beta$-BBO is very small, indicating that the lattice mismatch between the $c$-plane and $a(=b)$-plane is very small. However, $\beta$-BBO has a large anisotropic structure, in particular, the stacking of planar $\left[\mathrm{B}_{3} \mathrm{O}_{6}\right]^{3-}$ units along the $c$-axis direction, indicating a large difference in the atomic arrangement in the $a$-plane and $c$-plane, i.e., a large structural mismatch. It is, therefore, considered that the growth of the $c$-plane at the $a$-plane would be difficult structurally. This would be the reason that the $a$-plane of $\beta$-BBO crystals is created in the second line after crossing, as schematically shown in Figure 7. The relationship in the crystal growth direction at the crossing point between the first and second lines is expressed as the combination of the $a$-plane/ the $a$-plane of the same crystalline phase of $\beta$-BBO, and this crystal growth is regarded as "a homo-epitaxial crystal growth" in the crossing lines of nonlinear optical $\beta$-BBO crystals patterned by laser irradiation. The preferential crystal growth direction of $\beta$-BBO patterned by laser is the $c$-axis. Therefore, during the crystal growth in the second line, $\beta$-BBO tends to have the $c$-axis orientation. It would be difficult energetically to change the crystal growth direction from the $a$-axis to the $c$-axis in an instance at a given position, but the gradual change would be expected. Consequently, the transition zone for the $c$-axis orientation, i.e., from the $a$-axis orientation to the $c$-axis orientation, would be created. Finally, even in the second line, $\beta$-BBO crystals with the $c$-axis orientation would be patterned, as schematically shown in Figure 8. The phenomenon on the nucleation and crystal growth of $\beta$-BBO crystals in the second line after crossing is illustrated schematically in Figure 9. A similar behavior of homo-epitaxial crystal growth in the crossing lines patterned by laser irradiation has been reported in the patterning of nonlinear optical $\mathrm{BaAlBO}_{3} \mathrm{~F}_{2}$ crystals (Shinozaki et al., 2015). That is, the present study is the second example for the homo-epitaxial crystal growth

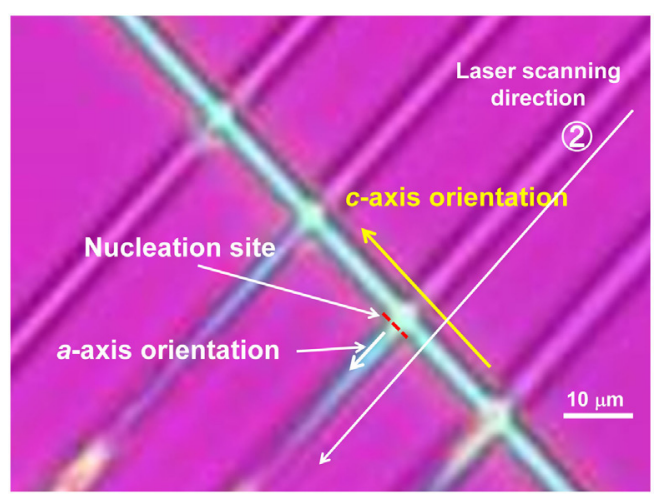

FIGURE 7 | POM photograph focusing the crossing points of the first and second lines. in the crystallization of glasses, and the homo-epitaxial crystal growth is regarded as a common feature in the laser-induced crystallization in glasses.

It should be pointed out that the behavior of hetero-epitaxial crystal growth in the crystallization of glasses has been found in $\mathrm{Li}_{2} \mathrm{O}-\mathrm{Al}_{2} \mathrm{O}_{3}-\mathrm{SiO}_{2}$ glasses containing $\mathrm{P}_{2} \mathrm{O}_{5}$ nucleation agent, in which the hetero-epitaxial growth of lithium metasilicate $\mathrm{Li}_{2} \mathrm{SiO}_{3}$ and lithium disilicate $\mathrm{Li}_{2} \mathrm{Si}_{2} \mathrm{O}_{5}$ on $\mathrm{Li}_{3} \mathrm{PO}_{4}$ crystals is found in heat treatment in an electric furnace (Headley and Loehman, 1984). There are many glasses that show the formation of two different kinds of crystalline phases in the crystallization. In such glasses, hetero-epitaxial crystal growth might be expected largely through the control of heat treatment. However, it should be pointed out that the design and control of the nucleation site and the crystal growth direction in the crystallization in an electric furnace would be difficult. On the other hand, in the laser-induced crystallization, which enables the heating position, direction, and period, the nucleation site and crystal growth direction might be designed and controlled more effectively. In particular, crossing line experiments are proposed to be a good technique for the

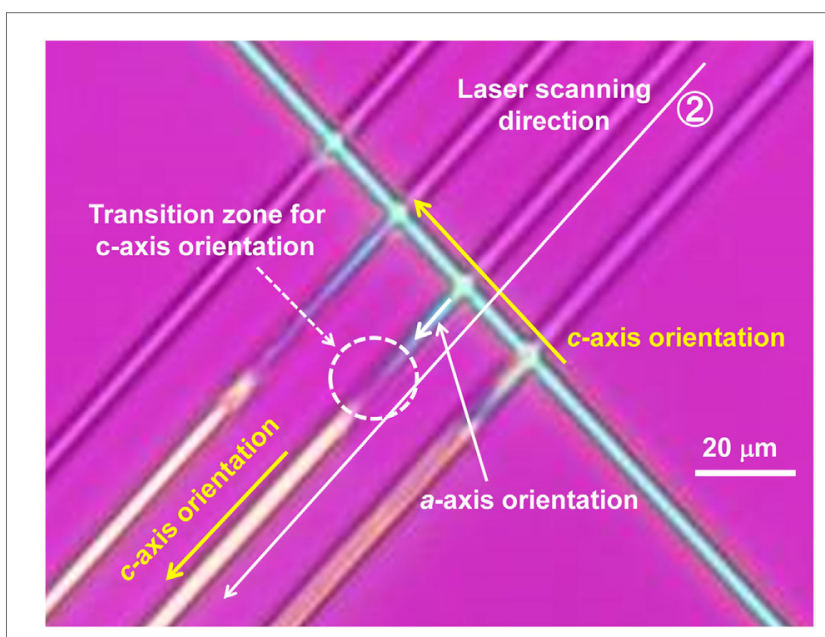

FIGURE 8 | POM photograph focusing the crossing points of the first and second lines.

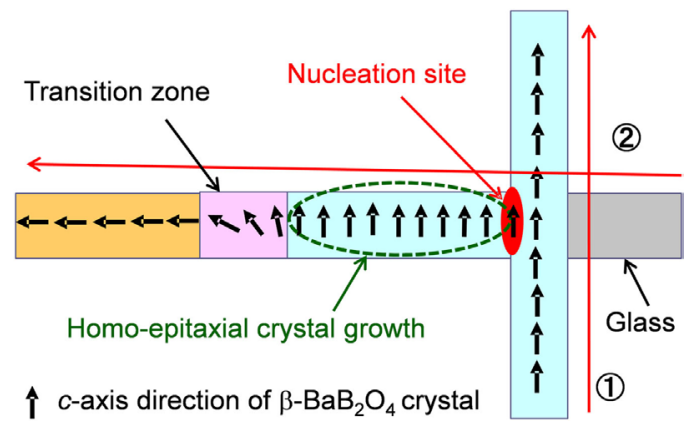

FIGURE 9 | Schematic illustration for the nucleation and crystal growth in the second line after crossing. 
study of nucleation and crystal growth in glasses as demonstrated in the present study.

\section{CONCLUSION}

Nonlinear optical $\beta-\mathrm{BaB}_{2} \mathrm{O}_{4}(\beta-\mathrm{BBO})$ crystal lines were patterned by continuous-wave $\mathrm{Yb}: \mathrm{YVO}_{4}$ fiber laser (wavelength $1080 \mathrm{~nm}$ ) in $8 \mathrm{Sm}_{2} \mathrm{O}_{3}-42 \mathrm{BaO}-50 \mathrm{~B}_{2} \mathrm{O}_{3}$ glass, and the nucleation and crystal growth behaviors in the laser-patterned crossing lines were examined from POM observations. The model of self-organized homoepitaxial crystal growth was demonstrated for the orientation of $\beta$-BBO crystals at the crossing point of two lines, in which the first crystal line at the crossing point acts as nucleation site for the second crystal line. The nucleation site and crystal growth direction are controlled effectively in the laser-induced crystallization.

\section{REFERENCES}

Beall, G. H., and Pinckney, L. R. (1999). Nano glass-ceramics. J. Am. Ceram. Soc. 82, 5-16. doi:10.1111/j.1151-2916.1999.tb01716.x

Cabral, A. A., Fokin, V. M., Zanotto, E. D., and Chinaglia, C. R. (2003). Nanocrystallization of fresnoite glass. I. Nucleation and growth kinetics. J. NonCryst. Solids 330, 174-186. doi:10.1016/j.jnoncrysol.2003.08.046

Deubener, J. (2000). Compositional onset of homogeneous nucleation in (Li,Na) disilicate glasses. J. Non-Cryst. Solids 274, 195-201. doi:10.1016/ S0022-3093(00)00188-5

Eimerl, D., Davis, L., Velsko, S., Graham, E. K., and Zalkin, A. (1987). Optical, mechanical, and thermal properties of barium borate. J. Appl. Phys. 62, 1968-1983. doi:10.1063/1.339536

Enomoto, I., Benino, Y., Fujiwara, T., and Komatsu, T. (2007). Chemically etched sharpened tip of transparent crystallized glass fibers with nonlinear optical $\mathrm{Ba}_{2} \mathrm{TiSi}_{2} \mathrm{O}_{8}$ nanocrystals. J. Ceram. Soc. Japan 115, 374-378. doi:10.2109/ jcersj.115.374

Fokin, V. M., Zanotto, E. D., and Schmelzer, J. W. P. (2003). Homogeneous nucleation versus glass transition temperature of silicate glasses. J. Non-Cryst. Solids 321, 52-65. doi:10.1016/S0022-3093(03)00089-9

Gupta, P., Stone, A., Woodward, N., Dierolf, V., and Jain, H. (2011). Laser fabrication of semiconducting ferroelectric single crystal SbSI features on chalcohalide glass. Opt. Mater. Express 1, 652-657. doi:10.1364/OME.1.000652

Headley, T. J., and Loehman, R. E. (1984). Crystallization of a glass-ceramic by epitaxial growth. J. Am. Ceram. Soc. 67, 620-625. doi:10.1111/j.1151-2916.1984. tb19606.x

Honma, T., Benino, Y., Fujiwara, T., and Komatsu, T. (2003). Technique for writing of nonlinear optical single-crystal lines in glass. Appl. Phys. Lett. 83, 2796-2798. doi:10.1063/1.1615833

Honma, T., Benino, Y., Fujiwara, T., Komatsu, T., and Sato, R. (2005). Crystalline phase and YAG laser-induced crystallization in $\mathrm{Sm}_{2} \mathrm{O}_{3}-\mathrm{Bi}_{2} \mathrm{O}_{3}-\mathrm{B}_{2} \mathrm{O}_{3}$ glasses. J. Am. Ceram. Soc. 88, 989-992. doi:10.1111/j.1551-2916.2005. 00166.x

Honma, T., Benino, Y., Fujiwara, T., Sato, R., and Komatsu, T. (2004). MicroRaman and photoluminescence spectra of $\mathrm{Sm}^{3+}$-doped $\beta-\mathrm{BaB}_{2} \mathrm{O}_{4}$ crystal lines written by YAG laser irradiation in glass. J. Phys. Chem. Solids 65, 1705-1710. doi:10.1016/j.jpcs.2004.04.010

Honma, T., and Komatsu, T. (2010). Patterning of two-dimensional planar lithium niobate architectures on glass surface by laser scanning. Opt. Express 18, 8019-8024. doi:10.1364/OE.18.008019

Honma, T., Komatsu, T., and Benino, Y. (2008a). Patterning of c-axis-oriented $\mathrm{Ba}_{2} \mathrm{TiX}_{2} \mathrm{O}_{8}(\mathrm{X}=\mathrm{Si}, \mathrm{Ge})$ crystal lines in glass by laser irradiation and their second-order optical nonlinearlities. J. Mater. Res. 23, 885-888. doi:10.1557/ jmr.2008.0135

Honma, T., Nguyen, P. T., and Komatsu, T. (2008b). Crystal growth behavior in $\mathrm{CuO}$-doped lithium disilicate glasses by continuous-wave fiber laser irradiation. J. Ceram. Soc. Jpn. 116, 1314-1318. doi:10.2109/jcersj2.116.1314

Höland, W., and Beall, G. H. (2012). Glass-Ceramic Technology, 2nd Edn. Hoboken, NJ: The American Ceramic Society, John Wiley \& Sons.

\section{AUTHOR CONTRIBUTIONS}

TK proposed the idea of this study and guided the experiments. $\mathrm{TK}$ and $\mathrm{TH}$ analyzed the experimental data and prepared the manuscript through the discussion.

\section{ACKNOWLEDGMENTS}

We thank Mr. Kazuki Ogawa for his experiments in the laserinduced crystallization and Dr. Kenji Shinozaki for discussion. This work was supported from the Grant-in-Aid for Scientific Research from the Ministry of Education, Science, Sports, Culture and Technology, Japan (No. 23246114, No. 15K13804) and by Program for High Reliable Materials Design and Manufacturing in Nagaoka University of Technology.

Inoue, T., Gao, X., Shinozaki, K., Honma, T., and Komatsu, T. (2015). Laser patterning of non-linear optical $\mathrm{Bi}_{2} \mathrm{ZnB}_{2} \mathrm{O}_{7}$ crystal lines in glass. Front. Mater. 2:42. doi:10.3389/fmats.2015.00042

Kanno, M., Honma, T., and Komatsu, T. (2009). Two-dimensional mapping of $\mathrm{Er}^{3+}$ photoluminescence in $\mathrm{CaF}_{2}$ crystal lines patterned by lasers in oxyfluoride glass. J. Am. Ceram. Soc. 92, 825-829. doi:10.1111/j.1551-2916.2009.03010.x

Komatsu, T. (2015). Design and control of crystallization in oxide glasses. J. NonCryst. Solids 428, 156-175. doi:10.1016/j.jnoncrysol.2015.08.017

Komatsu, T., and Honma, T. (2013). Laser patterning and characterization of optical active crystals in glasses. J. Asian Ceram. Soc. 1, 9-16. doi:10.1016/j. jascer.2013.02.006

Komatsu, T., Ihara, R., Honma, T., Benino, Y., Sato, R., Kim, H. G., et al. (2007). Patterning of nonlinear optical crystals in glass by laser-induced crystallization. J. Am. Ceram. Soc. 90, 699-705. doi:10.1111/j.1551-2916.2006.01441.x

Komatsu, T., Koshiba, K., and Honma, T. (2011). Preferential growth orientation of laser-patterned $\mathrm{LiNbO}_{3}$ crystals in lithium niobium silicate glass. J. Solid State Chem. 184, 411-418. doi:10.1016/j.jssc.2010.12.016

Maruyama, N., Honma, T., and Komatsu, T. (2008). Electronic polarizability and Judd-Oflt parameters of $\mathrm{Nd}^{3+}$ and $\mathrm{Er}^{3+}$ ions in transparent crystallized glasses with nonlinear optical $\mathrm{Ba}_{2} \mathrm{TiSi}_{2} \mathrm{O}_{8}$ nanocrystals. J. Chem. Phys. 128, 184706. doi:10.1063/1.2908231

Nishii, A., Shinozaki, K., Honma, T., and Komatsu, T. (2015). Morphology and orientation of $\beta-\mathrm{BaB}_{2} \mathrm{O}_{4}$ crystals patterned by laser in the inside of samarium barium borate glass. J. Solid State Chem. 221, 145-151. doi:10.1016/j. jssc.2014.09.031

Ogawa, K., Honma, T., and Komatsu, T. (2013). Birefringence imaging and orientation of laser patterned $\beta-\mathrm{BaB}_{2} \mathrm{O}_{4}$ crystals with bending and curved shapes in glass. J. Solid State Chem. 207, 6-12. doi:10.1016/j.jssc.2013.08.021

Sakamoto, A., and Yamamoto, S. (2010). Glass-ceramics: engineering principles and applications. Int. J. Appl. Glass Sci. 1, 237-247. doi:10.1111/j.2041-1294.2010.00027.x

Shinozaki, K., Abe, S., Honma, T., and Komatsu, T. (2015). Self-organized homo-epitaxial growth in nonlinear optical $\mathrm{BaAlBO}_{3} \mathrm{~F}_{2}$ crystal crossing lines patterned by laser in glass. Opt. Mater. 49, 182-189. doi:10.1016/j. optmat.2015.09.016

Shinozaki, K., Honma, T., and Komatsu, T. (2012). New oxyfluoride glass with high fluorine content and laser patterning of nonlinear optical $\mathrm{BaAlBO}_{3} \mathrm{~F}_{2}$ single crystal line. J. Appl. Phys. 112, 093506. doi:10.1063/1.4764326

Shinozaki, K., Noji, A., Honma, T., and Komatsu, T. (2013). Morphology and photoluminescence properties of $\mathrm{Er}^{3+}$-doped $\mathrm{CaF}_{2}$ nanocrystals patterned by laser irradiation in oxyfluoride glasses. J. Fluorine Chem. 145, 81-87. doi:10.1016/j. jfluchem.2012.10.007

Stone, A., Sakakura, M., Shimotsuma, Y., Stone, G., Gupta, P., Miura, K., et al. (2010). Formation of ferroelectric single-crystal architectures in $\mathrm{LaBGeO}_{5}$ glass by femtosecond vs. continuous-wave lasers. J. Non-Cryst, Solids 356, 3059-3065. doi:10.1016/j.jnoncrysol.2010.03.048

Suzuki, F., Honma, T., and Komatsu, T. (2013). Direct laser patterning of $\beta-\mathrm{BaB}_{2} \mathrm{O}_{4}$ crystals with high orientation in the inside of glass fiber. J. Am. Ceram. Soc. 96, 1339-1341. doi:10.1111/jace.12275 
Suzuki, F., Honma, T., and Komatsu, T. (2014). Unique crystal growth with crystal axis rotation in multi-ferroic $\beta^{\prime}-(\mathrm{Sm}, \mathrm{Gd})_{2}\left(\mathrm{MoO}_{4}\right)_{3}$ narrow lines patterned by lasers in glass. J. Phys. Chem. Solids 75, 954-958. doi:10.1016/j.jpcs.2014. 04.007

Suzuki, F., Ogawa, K., Honma, T., and Komatsu, T. (2012). Laser patterning and preferential orientation of two-dimensional planar $\beta-\mathrm{BaB}_{2} \mathrm{O}_{4}$ crystals on the glass surface. J. Solid State Chem. 185, 130-135. doi:10.1016/j.jssc.2011.11.005

Tsukada, Y., Honma, T., and Komatsu, T. (2009). Self-organized periodic domain structure for second harmonic generation in ferroelastic $\beta^{\prime}$ - $(\mathrm{Sm}, \mathrm{Gd})_{2}\left(\mathrm{MoO}_{4}\right)_{3}$ crystallines on glass surfaces. Appl. Phys. Lett. 94, 059901. doi:10.1063/1.3076080
Conflict of Interest Statement: The authors declare that the research was conducted in the absence of any commercial or financial relationships that could be construed as a potential conflict of interest.

Copyright (c) 2016 Komatsu and Honma. This is an open-access article distributed under the terms of the Creative Commons Attribution License (CC BY). The use, distribution or reproduction in other forums is permitted, provided the original author(s) or licensor are credited and that the original publication in this journal is cited, in accordance with accepted academic practice. No use, distribution or reproduction is permitted which does not comply with these terms. 